\title{
Clinical dilemmas and the Cochrane Collaboration
}

\author{
Clive Adams, Karla Soares and Irshad Ahmed
}

\begin{abstract}
Dilemma
A person suffering from schizophrenia is brought to a clinic by his family. The clinician may well give the person chlorpromazine or haloperidol. How useful, on average, is this treatment in the short term and in the long term? What is this person's chances, on average. of staying free of relapses at the end of a year and what is the probability of that person acquiring a relatively permanent and disfiguring movement disorder as a side-effect? Perhaps the person's illness is resistant to treatment. How useful is clozapine/ risperidone/olanzapine?
\end{abstract}

If you, like us, have difficulty answering the first set of questions, then the efficacy of the 'new generation' antipsychotic drugs, such as clozapine, will be even more in doubt. Currently, when you try and help people with mental illnesses or problems what guides your practice? Often, both professionals and 'lay-carers' use a combination of intuition, common sense, wisdom gleaned from experience and, to a greater or lesser extent. evidence. However, unsatisfled with this situation, clinicians, managers, policy-makers and consumers of care are looking for easily accessible, up-to-date, objective evidence regarding the effectiveness of interventions used in clinical practice (Mulrow \& Oxman, 1997).

\section{Sources of evidence of effectiveness}

Randomised controlled trials and reviews

Controlled trials, and specifically randomised controlled trials (RCTs) are the most powerful research design to evaluate effects of mental health care (World Health Organization Scientific Group on Treatment of Psychiatric Disorders. 1991). There are, however, too many RCTs published in too many journals for anyone to keep up-to-date (Sackett \& Rosenberg, 1995). In order to decrease the potential for bias or the play of random error (Chalmers, 1989), it is desirable to produce an overview of research findings. Frequently, those interested in the effectiveness of care depend on reviews in journals, textbooks or guidelines to direct practice. Generally speaking there are two sorts of reviews, the systematic and the traditional/ subjective.

\section{Systematic v. traditional reviews}

Systematic and traditional reviews are very different. The former will have a methods section. the latter may not. In a systematic review the means by which data are identified, selected and. if appropriate, assimilated is made explicit (Sackett et al, 1991). These methods are open to scrutiny and valid criticism.

The recommendations of systematically conducted reviews and traditional reviews may be quite contradictory. For example, for the management of those with myocardial infarction. Antman et al (1992) compared the recommendations of leading textbooks and journals to the results of what systematically conducted reviews would have said using the RCT data of the day. They found that leading traditional reviews, by omission, recommended interventions that were harmful or lethal up to 10 years after generally acceptable proof to the contrary was available. Similar examples are just beginning to emerge from within mental health. Up to now, some reviewers were recommending the use of vitamin $\mathrm{E}$ to treat neuroleptic-induced tardive dyskinesia (Lloyd, 1992; Jeste \& Caligiuri, 1993). A recently completed systematic review of the best available evidence suggests that vitamin $E$ could be anything from moderately helpful to very harmful (Soares \& McGrath, 1997). It certainly is an intervention worthy of full evaluation but. currently, there is little evidence to recommend its use.

\section{The Cochrane Collaboration}

The Cochrane Collaboration was launched in 1993 (Chalmers et al, 1992) with a view to the production, maintenance and dissemination of systematic reviews of health care. It consists of a global network of people methodically seeking every published or unpublished, complete or incomplete, controlled trial of health care. Groups of people with similar interests are forming to systematically review these studies. 
These groups are open to anyone wishing to invest effort.

At present, within the Cochrane Collaboration, there are five groups with a specific interest in mental health. The first, the Cochrane Schizophrenia Group, has been working for four years. It is composed of clinicians, researchers, occupational therapists, economists, nurses and consumers of care, widely dispersed across the world. The Cochrane Depression. Anxiety and Neurosis Group is focusing on affective and eating disorders, somatisation problems and deliberate selfharm. The Cochrane Dementia and Cognitive Impairment Group is focusing on the care of those with any type of illness that primarily effects cognitive functioning. These groups have a register of relevant clinical trials. The Cochrane Addiction Group and Cochrane Developmental, Psychosocial and Learning Problems Group are starting to build a register of trials and reviews. For example, the Cochrane Schizophrenia Group has undertaken a comprehensive and methodical search strategy to build its register and make it available to anyone interested in doing review within its scope. The Group is already producing, and updating reviews within the electronic output of the Collaboration, the Cochrane Library. Currently there are only 27 systematic reviews in the Cochrane Library directly related to people with severe mental illness. These reviews deal with not only pharmacological treatments (beta-blockers, clozapine, fluphenazine risperidone and zuclopentixol for schizophrenia; anticholinergics, benzodiazepines, calcium channel blockers, cholinergics, gamma-aminobutyric acid agonists, vitamin $\mathrm{E}$ and miscellaneous treatment for neuroleptic-induced tardive dyskinesia; antipsychotics for learning disability), but also with other forms of interventions such as case management, community mental health team management, family intervention, electroconvulsive therapy, intercessory prayer and long versus short hospitalisation for those with schizophrenia. In addition, nine protocols for schizophrenia and 13 for depression are available in this version of the Cochrane Library (Issue 1, 1998).

\section{Cochrane Library}

The Cochrane Library is an inexpensive electronic database, currently published every three months and distributed by Update Software (see Appendix). It contains several databases. The Cochrane Controlled Trials Register holds references to approximately 180000 randomised or quasi-randomised trials identified by the members of the Collaboration. The Database of Abstracts of Reviews of Effectiveness is a register of already published systematic reviews that have been identified by methodical searches of journals (currently with 1852 references). The Cochrane Database of Systematic Reviews is the flagship of the Library, it contains all reviews undertaken and maintained by those within the Cochrane Collaboration. The Cochrane Database of Systematic Reviews has been supplied to all National Health Service libraries in the UK and abstracts of reviews are also available on the Internet (http://cochrane.co.uk/info/abstracts/ abidx.htm). Mental health professionals and students can find this database and search for information regarding specific interventions for clinical problems. The Cochrane Database of Systematic Reviews is a new publication and is filling up with regularly maintained reviews and already is a powerful teaching tool for those interested in the evaluation of care.

\section{Back to the dilemma}

So, currently, when you try and help people with mental illnesses or problems what would you like to guide your practice? The application of up-todate evidence, along with intuition, common sense and wisdom, is increasingly desirable, and now possible.

The Cochrane Collaboration has been likened, for better or worse, to the Human Genome Project (Naylor, 1995). If the current expansion and effort of this organisation continues, the Cochrane Database of Systematic Reviews will soon contain hundreds of reviews relevant to all aspects of health care. It will clarify what is known, and what is not known, solve some dilemmas and make others more acute.

\section{Appendix: Useful addresses}

Cochrane Library: Update Software, PO Box 696, Oxford OX2 7YX; Tel: +44 1865513 902; Fax: +44 1865516 918; e-mail: sales@update.co.uk

Cochrane Schizophrenia Group: Ms Leanne Roberts, Summertown Pavilion, Middle Way, Oxford OX2 7LG; Tel: +44 1865 316776; Fax: +44 1865 316023; e-mail: leanne.roberts@ psych.ox.ac.uk

Cochrane Depression, Anxiety and Neurosis Group: Ms Natalie Khin, University of Auckland. Psychiatry and Behaviour Sciences, Private Bag 92019. Auckland, New Zealand; Tel: +64 9373 7599 x6543; Fax: +64 9373 7493; e-mail: n.khin@auckland.ac.nz

Cochrane Drugs and Alcohol Group: Ms Annette Verster, Osservatorio Epidemiologico Regione Lazio, Via S. Costanza, 53, 00198 Rome, Italy: Tel: +39 65168 6406; Fax: +39 65168 6463; email: oss.epid.reg.lazio@agora.stm.it 
Cochrane Dementia and Cognitive Impairment Group: Mr Peter Smith, Department of Geratology, Radcliffe Infirmary, Woodstock Road, Oxford: Tel: +44 1865 224863; Fax: +44 1865 224108; e-mail: peter.smith@geratology.ox. ac.uk

Cochrane Developmental, Psychosocial and Learning Problems Group: Professor Geraldine Macdonald, School for Policy Studies, University of Bristol, 8 Woodland Road, Bristol BS8 1TN; Tel: +44 117928 8489; Fax: +44 117928 8586; e-mail: geraldine.macdonald@bristol.ac.uk

Cochrane Collaboration on the Internet: http:// cochrane.co.uk/info/abstracts/abidx.htm (abstracts of completed reviews)

\section{References}

Antman, E. M., LAU, J., Kupelnick, B., et al (1992) A comparison of results of meta-analysis of randomized controlled trials and recommendations of clinical experts. Treatment for myocardial infarction. Journal of the American Medical Association, 268, 240-248.

Chalmers, I. (1989) Evaluating the effects of care during pregnancy and child birth. In Effective Care in Pregnancy and Childbirth (eds I. Chalmers, M. Enkin \& M. J. N. C. Keirse), pp. 3-38. Oxford: Oxford University Press.

Chalmers, I., Dickersin, K. \& Chalmers, T. C. (1992) Getting to grips with Archie Cochrane's agenda. British Medical Journal, 305, 786-788.

COCHRANE LIBRARY (1998) The Cochrane Collaboration (Issue 1) (database on disk and CD-ROM). Oxford: Update Software.
Jeste, D. V. \& CALugiuRI, M. P. (1993) Tardive dyskinesia. Schizophrenia Bulletin, 19, 303-315.

LLOYD, J. H. (1992) Tardive dyskinesia: current status and future directions. Australian Journal of Hospital Pharmacy, 22, 334-338.

Mulrow, C. D. \& OXMAN, A. D. (eds) (1997) Cochrane Collaboration Handbook (Issue 4). In The Cochrane Library (database on disk and CD-ROM). Oxford: Update Software.

NAYLOR. D. (1995) Grey zones of clinical practices: some limits to evidence based medicine. Lancet, 346, 840 842.

SACKETt, D. L., HAYNES, R. B., GuYATt, G. H., et al (1991) Clinical Epidemiology: A Basic Science for Clinical Medicine. Toronto: Little Brown.

SACKETT, D. L. \& RosenBERG, W. M. C. (1995) The need for evidence-based medicine. Journal of the Royal Society of Medicine, 88, 620-624.

SOARES, K. V. S. \& MCGRATH. J. J. (1997) Schizophrenia and neuroleptic induced tardive dyskinesia: efficacy of vitamin $E$. The Cochrane Database of Systematic Reviews (CD-ROM), Issue 1. Oxford: Update Software.

WORLD HEALTH ORGaNIZATION SCIENTTFIC GROUP ON TREATMENT OF PSYCHIATRIC DISORDERS (1991) Evaluation of Methods for the Treatment of Mental Disorders. WHO: Geneva.

*Clive Adams, Coordinating Editor, Cochrane Schizophrenia Group, Institute of Health Sciences, Summertown Pavilion, Middle Way, Oxford OX2 7LG; Karla Soares, PhD affiliate, Department of Psychiatry, Federal University of São Paulo, Brazil and Irshad Ahmed, Resident, Yale University Department of Psychiatry. USA

*Correspondence 